ص تقارير علمية

\title{
تحديث مصر فى ظل المتغيرات العالمية الجديدة
}

\section{عرض: مجدى محمد خليفة*}

|||||||||||||||||||||||||||||||||||||||||||||||||||||||||||||||||||||||||||||||||||||||||||||||||||||||||||||||||||||||||||||||||||||||||||||||||||||||||||||||||||||||||||||||||||||

\section{تناول المؤتم عدة أوراق بحثية :}

الورقة الأولى قدمها د. حمدى عبد العظيم وتناول فيها دور اتفاقية المشاركة المصرية الأوربية

$$
\text { فى لحديث تطاع الصناعة وقد عرضت الموضوع من خلال خمسة محاور رئيسية :- }
$$

- استـعرض المحور الأول مـامع اتفاقيـة المثـاركة المصرية الأوربية من حيث تأثيـرها على ألى المنتـجات الصناعـيـة سـواء كان هذا التـأثير سلبا أو ايجابا ، أيضـا تأثير الاتفاقيـة على المنتـجات الزراعية خاصة البرتوكولات التى تخضع لها ، وحق تأسيس الشركات والامداد بالحدمات سواء كانت شركات مشتركة أى شركات يقيمها أى طرف لدى الطرف الآخر. كذلك أوضحت الورقة فى هذا المحور أن الاتفات تضمن حركة رأس المال وتسـوية المدفوعات بين الطرفين سواء كانت مدفوعات جارية أو عمليات خاصة بحساب رأس المال وتحركاته منذ بدء سريان الاتفاقية، وأكدت على أنه يجوز لأى من الطرفين وضع قيود مؤقتة لفترة محدودة على المعاملات الجارية لعلاج الصعويات التى تواجه ميزان المدفوعات. وذكرت الورقة أن اتفاقية الشراكة استهـدفت دفع التعاون الاقتصادى بين الطرفين بهدف تحقيت التنميـة الاقتصـادية والاجتـماعيـة المتـواصلة خاصة فى الاقتصاد المصرى. وتعرضت الورقة لمجالات التعاون الاقتصادى ووسائله وكذلك التعاون فى مجال التدريب والتعليم ومجال التعاون العلمى والفنى والتكنولوجى والبيئى. كما تعرضت إلى مجالات التعاون المختلفة وكانت أهمها: - التعاون فى المجالات العلمية والفنية والتكنولوجية والمالية.

* أ.د. مجدى محمد خليفة : مستشار بركز العلاقات الاقتصادية الدولية - معهد التخطيط القومى. 
- التعاون البينى والصناعى وحماية الاستثمار. - التعاون فى مجال التوحيد القياسى والتقريب بين النظم الضريبية.


- التعاون فى مجال الزراعة وصيد الأسماك. - التعاون فى مجال النقل وتطبيق معايير التشغيل. - التعاون فى مجال تكنولوجيا الاتصالات والمعلومات والاحصائيات وقواعد البيانات. - التعاون فى مجال الطاقة المتجددة والبحوث التطبيقية وتطوير شبكات الطاقة. - التعاون فى تنشبط السياحة والتسويق السياحى وتشجيع سياحة الشباب. - التعاون فى مجال الجمارك وتبسيط اججراءاتها.

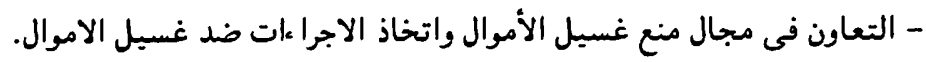
- محاربة المخدرات واستخدامها والاتجار فيها. وتناول المحور الثانى من الورقة الآثار المتوقعة للاتفاقية على الاتتصاد المصرى، حيث ركز

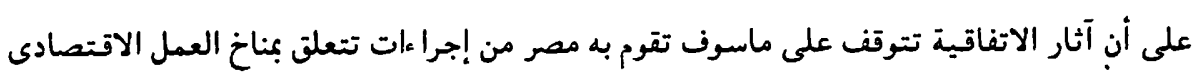
الداخلى واسلوب ادارته وأهم هذه الاجراءات الآتى: - توفير المناخ الملاتم للاستفادة من الاتفاقية ووضع الآليات الكفيلة بتنفيذها لتعظيم هذه الاستفادة.

واكد هذا المحور على امكانية الاستفادة من الاتفاقبة فى زيادة الصادرات المصرية إلى دول السوق الأوربية، بالإضافة الى زيادة حصول مصر على المساعدات الانتمانية من دول السوق وامكانية تعميق التصنيع ونقل التكنولوجيا الى القطاع إلصناعى والزراعى وأيضا زيادة تدفق الاستخمـارات

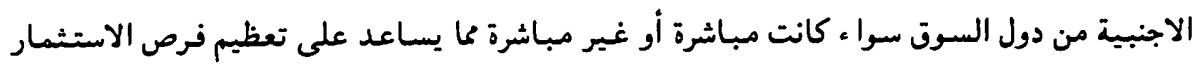
والتوظف فى مصر وزيادة الدخل القومى ورفع مستوى المعيشة.

وشرح المحسور الثـالث من الورقة البرنامج المصرى لتطوير وتحديث وتنميـة القدرة التنافسيـة للصناعة المصرية، حبث تم عرض الملامح الرئيسية للبرنامج الكامل للتعامل مع المتغبرات العالمية


rvi 


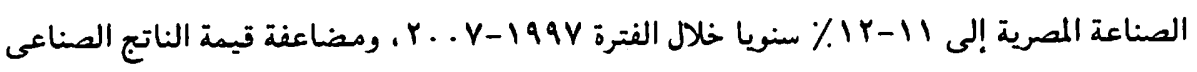
خلال نفس الفترة. أيضا وصول الصادرات الصناعية إلى مايقرب من ثلاثة أمثال ماهى عليه الآن فى

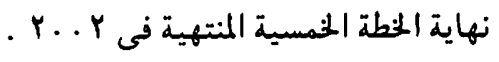

كذلك تم عرض البرنامج الشامل لتحديث الصناعة وتنمبة قدرتها التنافسية والذى يرتكز على ثلاثة محاور هى : - تحديث وتطوير وتنمية المشروعات الصغيرة والمتوسطة. - تنمية البيئة التكنولوجية وتحسين البنية الأساسية للجودة الصناعية. - انشاء واستكمال البنية الأساسية الصناعية اللازمة للخريطة الصناعية.

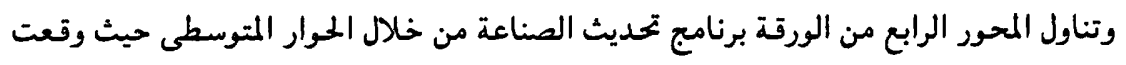


دول شمال وجنوب البحر الأبيض المتسوسط وذلك فى ديسمبر 1991 يقدم الجمانب الأوربى بمقتشضاه



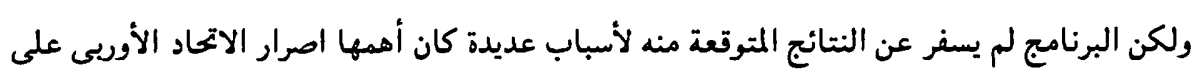

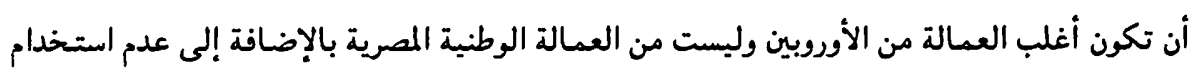


واستعرض المحور الخامس من الورقة كيفية الاستفادة من اتفاقية المشاركة فى تحديث قطاع



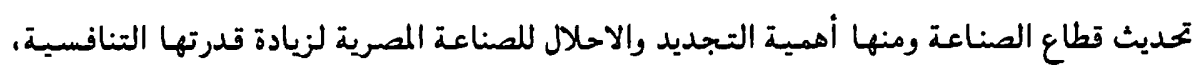

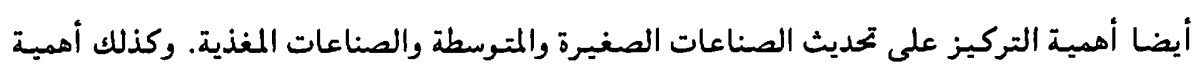

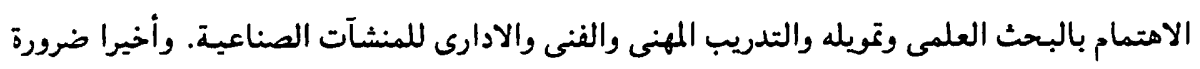

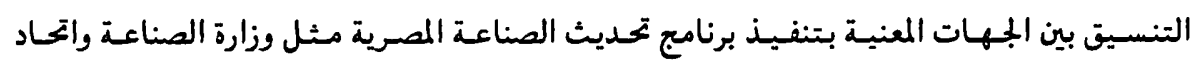


ووزارة قطاع الأعمال العام ووزارة المالية والتخطيط وغيرها من الجهاتيدات الجيات المعنية بذلك. 
أما الورقة الثانية فقدمها د. عبد المطلب عبد الحميد تناولت يحديث آلية الجهاز المصرفى للتكيف مع اتفاقية تحرير تجارة المثلمات حيث استعرضت مفهوم تحرير تجارة الخدمات ونطاق التطبيق

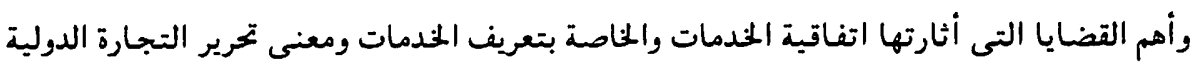
في المدمات وكذلك مضمون عملية التحرير بالنسبة للخدمات ثم. انتقلت الورقة إلى إلقاء الضوء

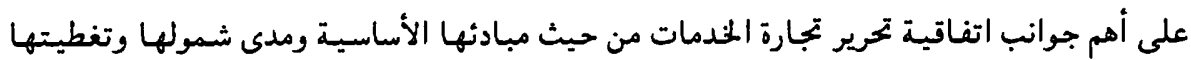


والارتباطات سوا ء كانت التزامات عامة أو محددة. ثم تطرقت الورقة إلى التزامات مصر نحو اتفاقية

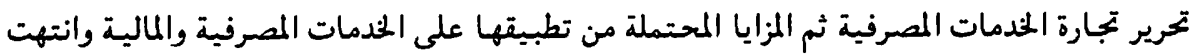

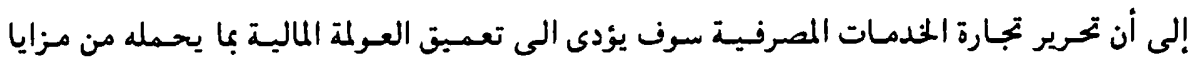



بعد ذلك أوضحت الورقة أهمية الحاجة إلى تحديث البنوك لمواجهة التحديات النابجة عن تحرير

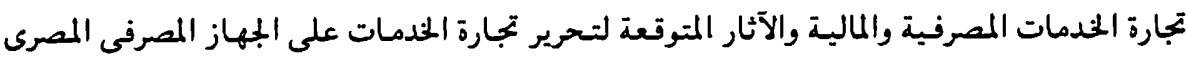
مع عرض هيكل وطبيعـة الجههاز المصرفى المصرى والإشـارة إلى الآراء المتفـائلة والمتشـائمسة والآثار

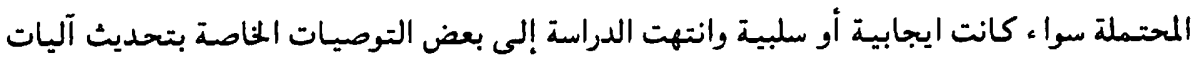
الجهاز المصرفى من خلال مداخل عديدة كان أهمها: - التحول إلى البنوك الثاملة ذات المدمات المتنوعة والمتطورة. - الاهتمام بالمستحدثات المصرفية الحديثة. - تقوية شبكة المعلومات المصرفية. - تنمية مهارات العاملين بالبنوك واعداد الكوادر المصرفية على مستوى عالمى. - تقوية دور البنك المركزى فى مرحلة تحرير الخدمات المصرفية. - تقوية قاعدة رأسمال البنوك وزيادة عملبة الاندماج المصرفى. - زيادة القدرة التنافسية للبنوك المصرية.

وقدم د. سعبـد عبد الخالق الورقة الثالثة والتى ركز فيـها على تنمية الاقتصاد المصرى،

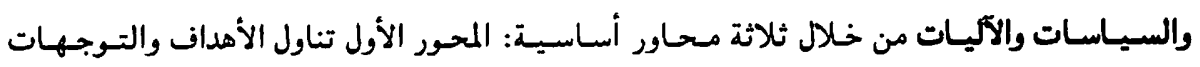
الرنيسية للتنمية الاقتصادية حيث حدد الأهداف الأساسية للسياسات الاقتصادية والتى كان أهمها 
تدعيم قدرة الدولة على تحقيق النمو المرتفع والمتواصل وتعزيز دور القطاع الحاص فى التنمية والنمو



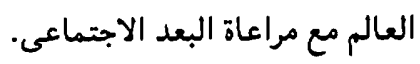
وركز المحور الثانى على السياسات الاقتصادية وآلياتها من خلال زيادة حجم الاستثمارات،

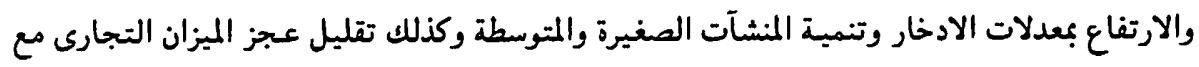
تعزيز دور المؤسسات وتنمية القوى البشرية. أما المحور الثالث فاستعرض مؤشرات الأداء الاقتصادى والتى تحسنت نتبجة للسياسـات

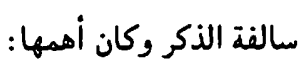



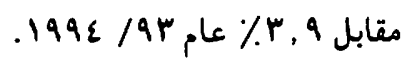



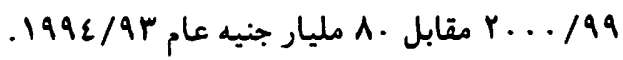

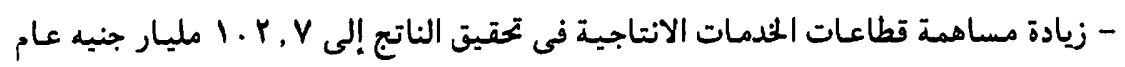

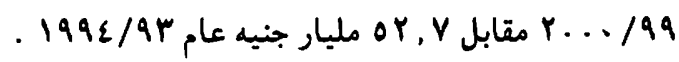

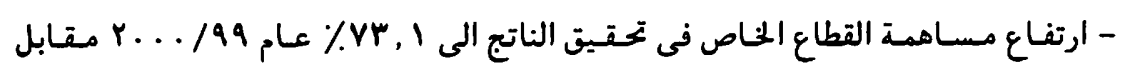

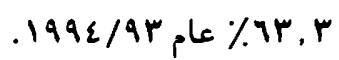

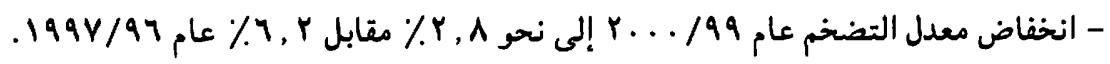

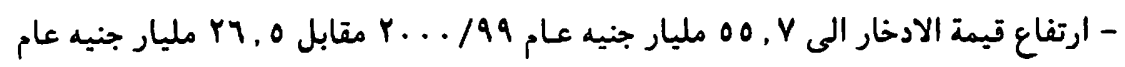
. 1992/arr





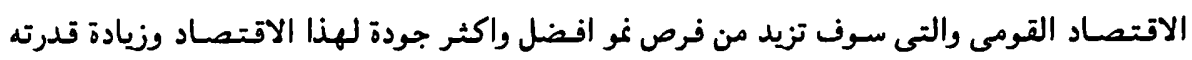
التنافسية. وكانت الورقة الرابعة والمقدمة عن التطورات المالية الدولية ويحديث التطاع المالى المصرى والتى 
قدم فيها د. نبيل حشاد تصورا عن وضع القطاع المالى العالمى فى بدايات القرن الحادى والعشرين

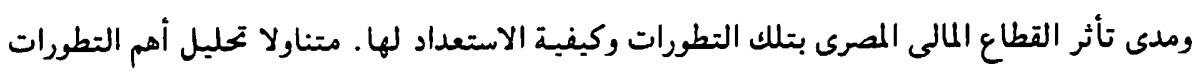
والاتجاهات المالية الدولية حاليا ومستقبلا من خلال مدى تزايد سرعة درجة العولمة المالية، والاتفاقية

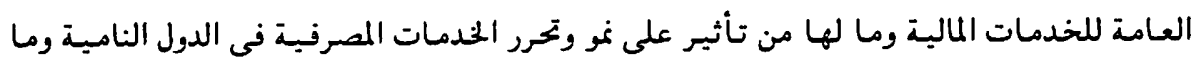

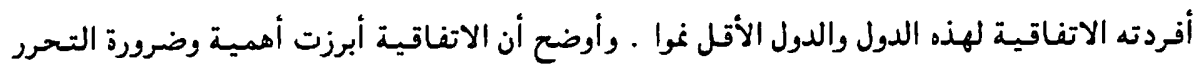

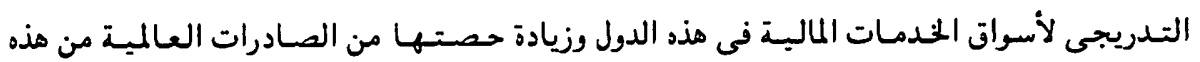


أسواقها المالية وتحسين قدرتها على الدخول إلى قنوات التوزيع وشبكات المعلوماتية. كما تناولت الورقة التطورات المصرفية سواء على المستوى العالمى أو على المستوى العربى مع

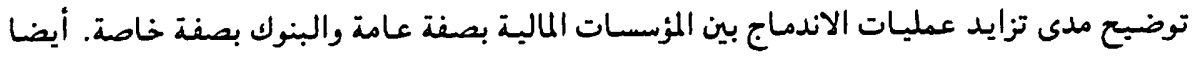
انتشار ظاهرة البنوك الشاملة وانخراط كثير من البنوك العالمية فى أعمال مؤسسات الوسائط المالية







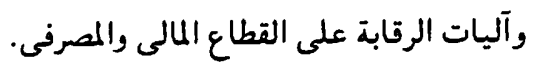

وفى هذا الصدد تناولت الورقة الاصلاحات الهيكلية والمؤسسية التى شهدها القطاع المصرفى


النوعى للجهاز المصرفى المصرى وكذلك سوق الأوراق المالية المصرية. وانتهت الدراسة الى مجموعة من المقترحات والتوصيات لتحديث القطاع المالى المصرى تناولت القطاع المصرفى والبورصة حيث ركزت على التالى: بالنسبة للقطاع المصرفى كانت أهم المقترحات اعطاء درجة أكبر من الاستقلالية للبنك المركزى

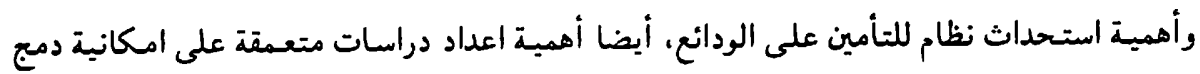

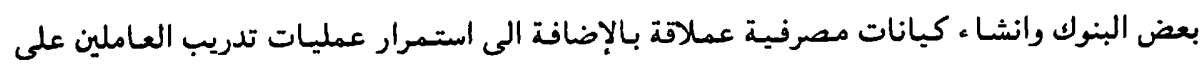
أهم مستحدثات العمل المصرفى. 
أما بالنسبة للبورصة فكانت أهم المقترحات ضرورة توعية المستـشمرين بالجموانب المختلفة

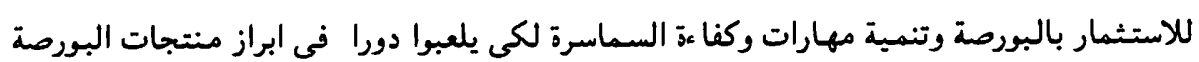

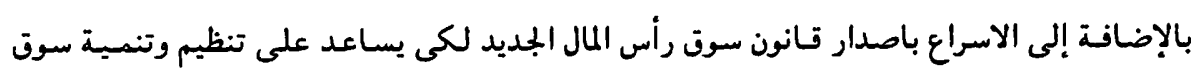
الأوراق المالية.

أما الورقة الخامسة فقدمها د. عبد الغاطى لاشين عن الاداره الاستراتيجية للاحتصاد القومى

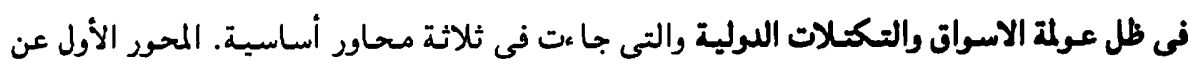





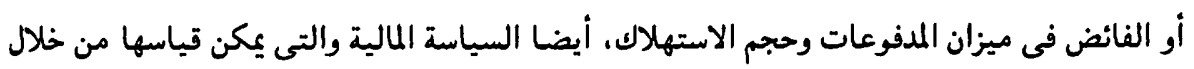
مقدار العجز فى الموازنة العـامة للدولة كنسبة من الدخل القومى ثم السيـاسة النقدية والتى يكيكن قباسها من خلال حجم القاعدة النقدية ومعدل دوران النقود ومعدل التضخم وسعر الفائدة على الودائع والقروض وسعر صرف العملة الوطنية. وتناولت الورقة فى نفس المحور العلاقة بين المتغيرات الاقتصادية والمالية والنقدية والتى يمكن

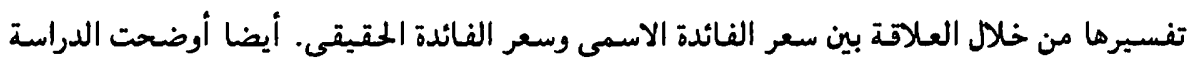

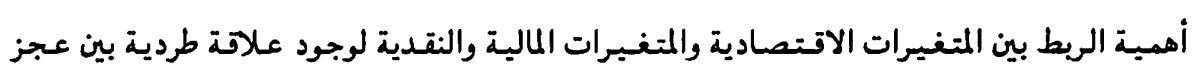
الموازنة العامة للدولة وسعر الفائدة فى السوق. أيضا أوضحت الدراسة أن نمو القاعدة النقدية بععدل


وعرضت الدراسة فى محورها الثانى كيفية تحويل الاقتصاد المصرى إلى مركز تجارى ومالى

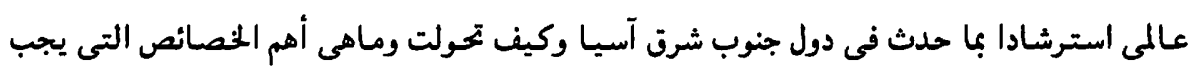
توافرها لوجـود مركز مالى عالمى والاعتبارات التى يجب توافرها فى المراكز التبجارية العالميـة. واقترحت الدراسة بعض التوصيات لتحويل منطقة شمال غرب خليج السويس الى مركز تجارى ومالى مالى

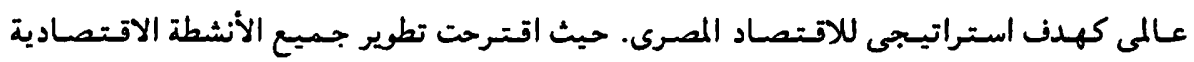
والاجتماعية فى الدولة لكى يكن تحويل هذه المنطقة الى مركز تجارى مالى عالمى. واقترحت الدراسة

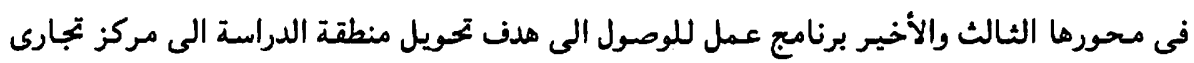


مالى عالمى يرتكز على مجموعة أنشطة هى:

نشاط التجارة الدولية والثقافة العربية والنقل البحرى والبرى والتركيز على الدول الاسلامية

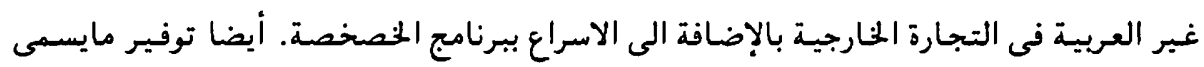



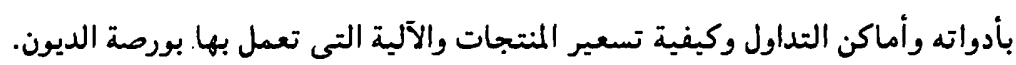
أيضا تعرضت الورتة ضمن برنامج العمل لمقومات سوق الصرف الأجنبى لعملات دول العالم


السويس إلى أحد المراكز التجارية العالمية المالية.

وقدمت الدكتهورة زينب أحمـد عزيز دراسة عن تحديث منظمات الاعبمال فى ظل المتغبرات

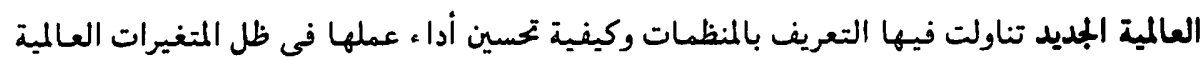

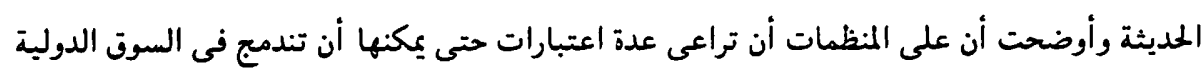
وتحقق التنافسية والميزة النسبية ـ ومن أهم هذه الاعتبارات الآتى: - العمل فى ظل سوق الكترونى عالمى.

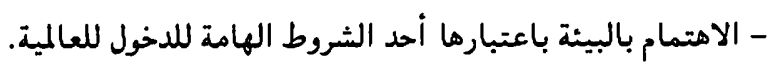
- أهمية التكامل الديناميكى لشبكة امدادات الموردين.

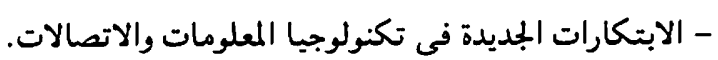




- العملاء شركاء.

- وضع روية وأهداف واضحة. كما أضافت الورقة بعض الاعتبارات الأخرى الخاصة بقبـادة المنظمة منها الروية المشتـركة والتركيز على الافراد والقيادة المشتركة والقيادة التعليمية. وانتهت الدراسة الى مجموعة من التوصيات أهمها: - اهمية تحديث منظمات الأعمال. 


$$
\text { - أن يتم تغيير صفات القيادة فى المنظمة. }
$$

- توفير الكوادر الادارية الجديدة ذات المستوى العالى من الكفاءة والمرونة القابلة للاستجابة للمتغيرات الحديثة.

أما الورقة السابعة فقدمها د. فريد النجار عن اعادة الهيكلة التكنولوجية للشركات كأساس





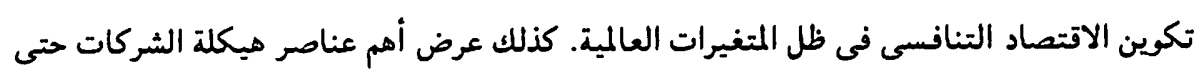
يكنها التكامل مع الاقتصاد العالمى ومنها: - المديرون والفجوة التكنولوجية المعاصرة. - نظريات التكنولوجيا المعاصرة. - الاستخبارات التكنولوجية. - المراجعة الدورية للتكنولوجيا. - الاهتمام بالاقتصاد التقنى. - آلية الشركات عابرة القارات فى نقل التكنولوجيا. - تحليل تجارب الشركات العالمية فى نقل التكنولوجيا. - التعرف على أنواع معلومات العلوم والتكنولوجيا. - أهمية تطبيق تكنولوجيا الاداره المعاصرة. - أهمية دراسة تأثير الشركات فائقة التكنولوجيا على تكنولوجيا الادارة المعاصرة. - أهمية دراسة التكامل التكنولوجى من خلال الشركات فائقة التقنية. - أهمية وضع الشركات المحلية تحت المجهر. - وضع أسس الهيكلة التكنولوجية للشركات.

وحول تحديث القضا ، المصرى لمواجهة جرائم المعلوماتية قدمت عايده حنا جرجس الورقة الثامنة

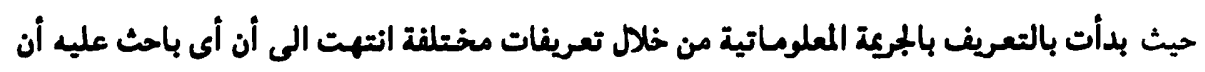

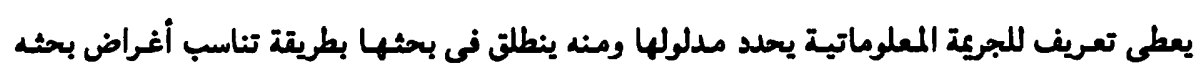


وتستخدم الأساليب والمناهج الملائمة للمجال وعرضت ثلاثة أنواع من التعريفات. - تعريفات متمركزة حول وسيلة ارتكاب الجرية. - تعريفات متمركزة حول توافر المعرفة بتنقية المعلومات. - تعريفات متمركزة حول موضوع الجريمة المعلوماتية .

وفى المبحث الثانى من الدراسة تناولت بعض صور الجرائم المعلوماتية التى يككن أن يواجهها

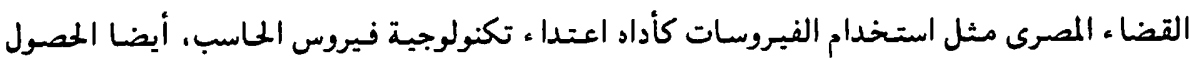

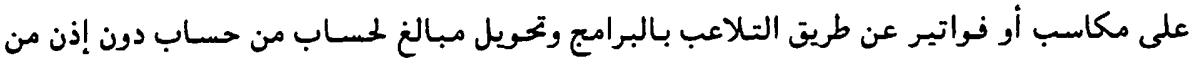
صاحب المساب الأصلى (أسلوب سلامى) .

وفى المبـحث الثـالث عرضت الوسـائل المقتـرحة لتحديث القضضاء المصرى لمواجهـة تضضابا المعلوماتية من خلال عدة فروع مثل اصدار تشريع يعالج جرانم المعلوماتية - التعاون القضائى الدولى لمرئي - الفرع الثالث التوسع فى تدريب القضاه وخبراء وزارة العدل.

وكانت الورقة التاسعـة مقدمهـ من د. مـحمد عبد الرازق الغوابى عن موضـوع استختدام

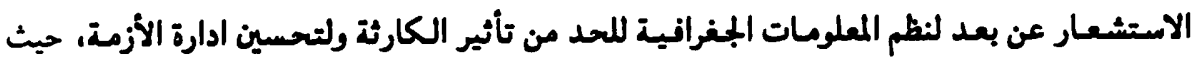
استهدف فى دراسته توضيح دور التقنيات الحديثة للاستشعار عن بعد ونظم المعلومات الجنغرافية للحد من تأثير الكارثة عند وقوعها أو الحيلولة دون وقوعها. وبالتالى فإن ادارة ومواجهة الأزمة الناجمة عنها بتخطيط سليم ويسرعة فى اتخاذ القرار وكفاءة عالية فى الحركة هى أهم عناصر نياح ادارة الأزمات.

وبدأت الدراسة فى تناول الاستشعار عن بعد كأحد المحاور الرئيسية فى التوقع بالكارثة وذلل



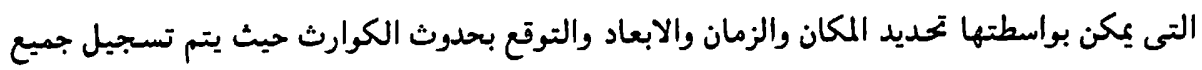

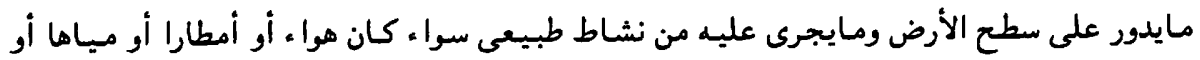

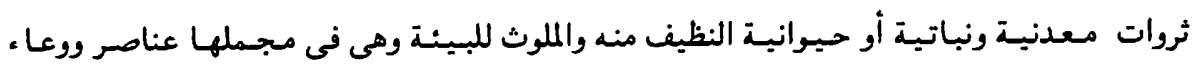
الكوارث بجميع أنواعها وأيضا فى نفس الوقت عناصر استمرار حياه الانسان على سطح الأرض. وركز المحور الثانى على أهمية نظم المعلومات الجغرافية ودقة بياناتها وتحديد مكانها وشدتها 
وغزارتها وتسبـيلها فى مراحل زمنبة متتـالية بحبث تكون ممثلة قدر الإمكان لواقع الحال حتى

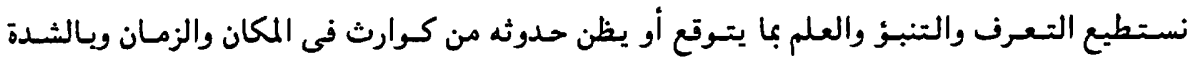

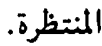

وكان المحور الثالث حول تحديد الكوارث البيئية مثل الكوارث الطبيعية والكوارث الناجمة عن النشاط البشرى الصناعى والزراعى والتعدينى أو الكوارث الناشئة عن الجهل بطبيعة المكان والشروط لئيل اللازمة لممارسة النشاط عليه والكوارث الناجمة عن الجهل والاهمال وخاصة الغش فى مواد البناء والاستهانه بالتعرن الخاطى، على المخلفات الصلبه والسائلة.

وتناولت الدراسة فى محورها الرابع طرق استشعار مقدمات الكوارث ومنها: - ضرورة توافر خريطة المكان الطبوغرافية الكنتورية. - رسم خرائط المكان الحالية وحصر بياناتها وتوصيفها. - تجميع بيانات وخرايط المكان عبر الأزمان السابقة. - تيديث بيانات وخرائط المكان أولا بأول.

ثم استعرض المحور الخامس طرق التنبز بالكوارث من خلال ثلاث طرق أساسية: - مقارنة ومطابقة خرايط المكان عبر الزمان. - انتاج خرانط تكاملية لبيئة المكان. - استنباط سيناريوهات متعددة كبدائل للتغيرات المنتظر حدوثها فى المستقبل. وقـد تم حصر طرق اداره الأزمات الناشئـة عن الكوارث الطبيعيـة أو الكوارث الناجمـة عن النشاط البشرى. وانتهت الدراسة الى أن تطبيق تقنيات الاستشعار عن بعد نظم المعلومات الجغرافية

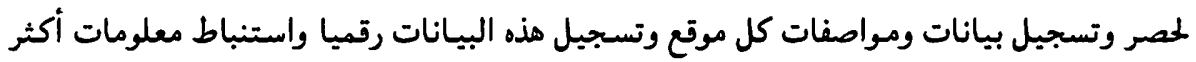
دقة عن شدة واتجاه ومعدل الكوارث المنتظرة للموقع المستهدف ووضعها على هيئة خرانط ثم مطابقة


الوسائل لادارة الأزمات الناجمة عنها.

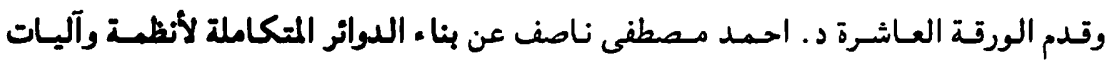
التكنولوجيا المعلوماتية فى حماية البينة واستدامة التنـية فى مصر وتهدف الورقة الى طرح رؤية 
لبنا ء الادارة البيئية المتكاملة التى تعمل فى ظل النظريات الاقتصادية والادارية المعاصرة حتى يككن

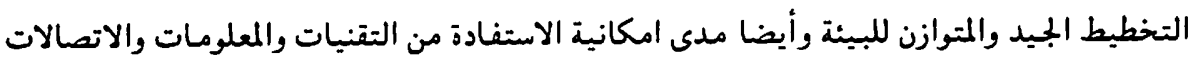


الواحد والعشرين.

تناولت الورقة فى محورها الأول الحاجة إلى العمل المنظومى المتكامل فى ادارة حماية البيئة

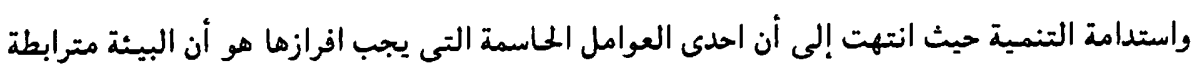

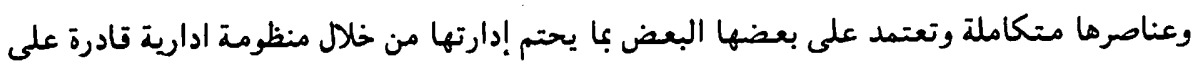

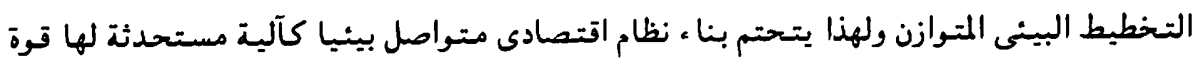



أما المحور الثانى من الدراسة فاستعرض الروافد الأساسية لبنا ، التكنولوجيا الملاتمة لحماية البيئة واستقرار التنمية موضحا أن عملية انشاء نظم للمعلومات لدعم الاداره البيئية يتم من خلال

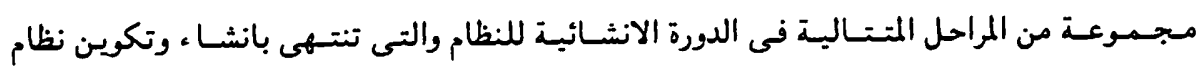
للمعلومات. ويتكون هذا النظام من أربعة أجزاء هى: - اعداد الدراسات التحليلية وتصميم البرامج وتعديلها.


والأجهزة والمعدات. - تحديد الاحتباجات وتوصيف الخدمات للمستفيدين من مستخدمى النظام. - تحديد نوعى وكمى للبيانات المتواجدة فى الفترة الحالية والقادمة. وتركز المحور الثالث حول نموذج متكامل للإدارة البيئية فى منظمات القرن الواحد والعشرين من

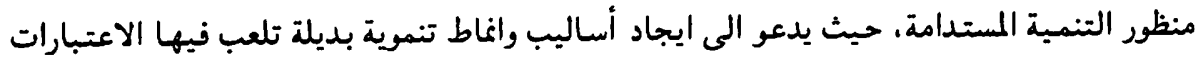

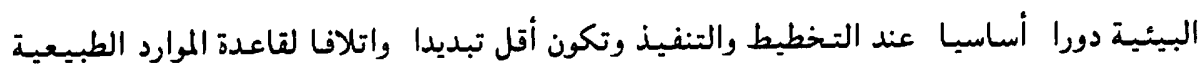
التى ترتكز عليها عملية التنمية ذاتها وذلك من خلال دمج البعد البينى فى عمليات اتخاذ القرارات والتخطبط ببرامج التنمية لدى كافة المستويات الاستراتيجية والتنفيذية. وعرض المحور الرابع من الورقة تطبيقات ونتائج تكنولوجيا المعلومات والاتصالات فى حماية 
البيئة وآثارها على استمرارية حياة المشروعات الاقتصادية حيث أكد على الأهمية القصوى أو الدور

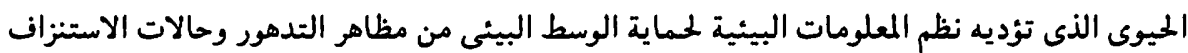


على أنظمة متكاملة للمعلومات البيئية.

وانتهت الدراسة إلى ضرورة إعادة تصميم نظام للادارة البينية الكلية من حيث تحديد الأهداف


يؤخذ فى الاعتبار معيار التوازن البيئى الانمائى عند تقيبم المشروعات فى ظل معايير الجودة الكلية فى مراحل الاعداد والتنفيذ والتشغيل والمتابعة.

وقدم البحث الحادى عشر سمير سعد مرقص عن استخدام الاستراتيجيات الضريبية فى إحداث التكيف الهيكلى لتحديث مصر من حيث وضع إطار لاستخدام الأثر الضريبى وتوظيفه من خلال التحديث المباشر عن طريق جذب وتنمية التكنولوجيا وتعميق التصنيع ودور الأثر الضريبى فى ذلك. جاء البحث فى أربعة فصول تناول الفصل الأول الاستراتيجيات الضريبية والتكييف الهيكلى موضها

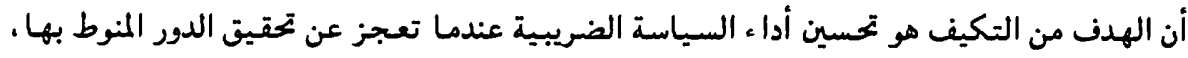



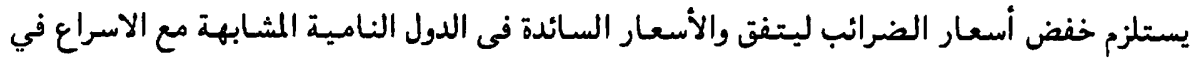
عمليات التحاسب الضريبى وتبسبط الاجرا ات مع تطوير الادارة الضريبية بشكل جذذرى وسريع والقضا ، على ظاهرة التهرب الضريبى . ويجب استبدال ذلك بالمحفزات الضريبية الداعمة للاستئمار

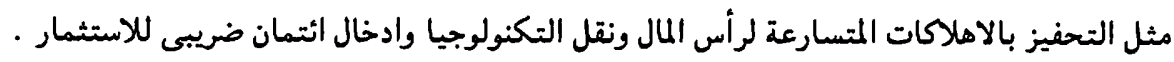
واستعرض الفصل الثانى الدور المباشر للحصيلة الضريبية فى تمويل التحديث مع توضيح أهمية

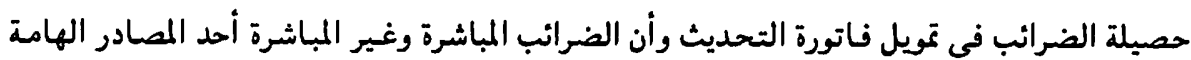
للتمويل فى الدول النامية .

وكان الفصل الثالث عن دور الضرائب المباشرة فى تحديث مصر حيث عرض أهميتها في جذب



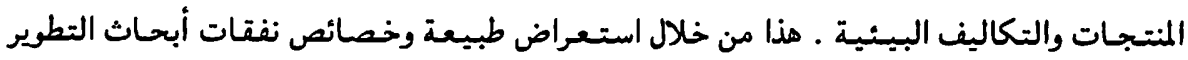


وتعميم المنتجات والعلاقة بين البحوث والتطوير والمعالجة المسابية لنفقات البحوث وتعميم المنتجات. أيضا دور الضرائب في تعميق التصنيع من خلال حسابات الاهلاك الاضافى والاهلاك المعجل وأثرهما



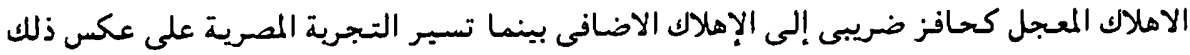

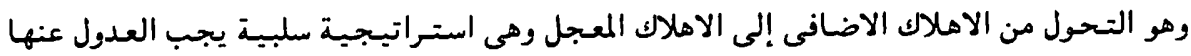

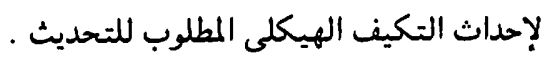

وتناول الفصل الرابع دور الضرانب غـيـر المباشـرة فى تحـديث مصر مستـعرضـا الاعفـاءات

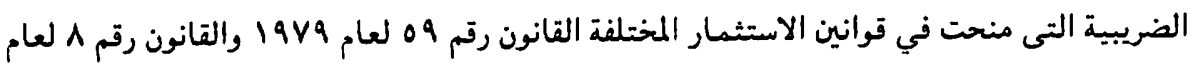

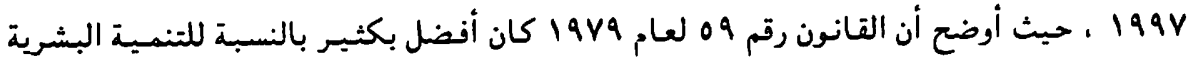





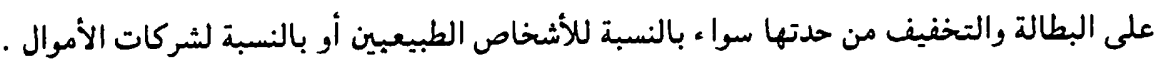
ثم شـرح هذا الفصل دور الضرائب فى زيادة الصادرات والاحهلال محل الواردات حيث انتهى الفه



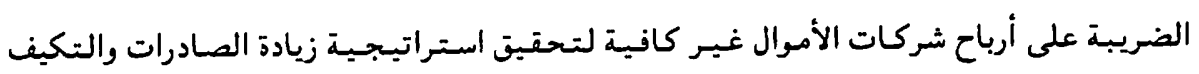


.

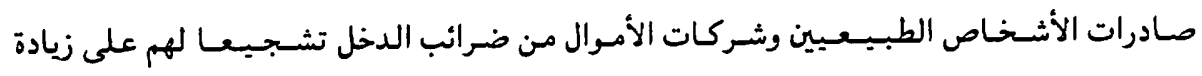
الصادرات.

وحول استراتيجية تحديث نظم وآليات العمل فى مجال الضراتب العامة قدم د. فتحى همام محمود الورقة الثانية عشرة والتى تناول فيها هذا الموضوع من خلال ثلاثة محاور : - المحور الأول تحديث التشريعات الضريبية وذلك من خلال احلال مفاهيم ضريبية متطورة محل المفاهيم القاصرة عن التجاوب مع مراحل التطور الاقتصادى والاجتماعى الحالية وذلك من خلال

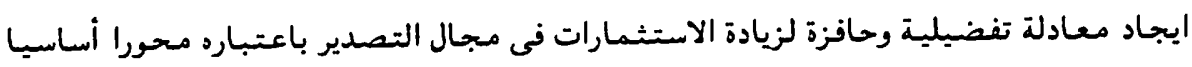


للتنمية. أيضا انعاش البورصة باعتبارها سوقا هاما للأورات المالية وممولا هاما للاستثمارات وجاذبا

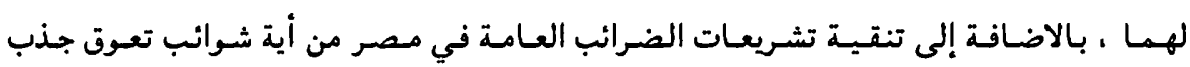

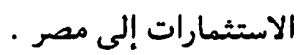

- المحور الثانى هو تحديث نظم وآليات العامل في الادارة الضريبية ، وذلك لزيادة انتاجية العاملين فى المأموريات وزيادة حصيلة الممولين وحل مشاكل التقدير فى حالات عدم تقديم الاقرارات التيات ومكافحة التهرب الضريبى ورفع مستوى الالتزام الضريبى الطوعى لدى الممولين ـ ولهذا فإن مصلحة

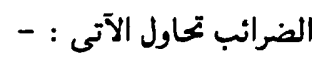

- استخدام أجهزة الميكروفيلم لتطوير أرشيفات العمل بالمصلحة . - تطوير نظم اختبار وتدريب القوى البشرية بصلحة الضرائب . - وضع قواعد جديدة للتحاسب الضريبى لبعض الأنشطة . - اجراء تعديلات على الهيكل التنظيمى لمصلحة الضرائب .





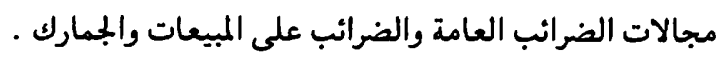

وتناوز المحور الثالث رفع مستوى الوعى الضريبى وذلك من خلال حملات اعلامية مكثفة

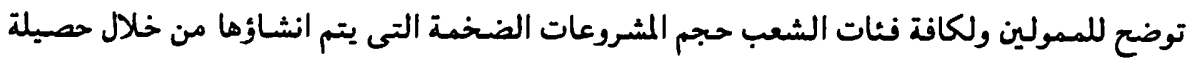


الدخل . - إعداد برنامج متكامل يتم ادخاله على شبكة الانترنت يوضح أهم مـلامح ونصوص قـانون

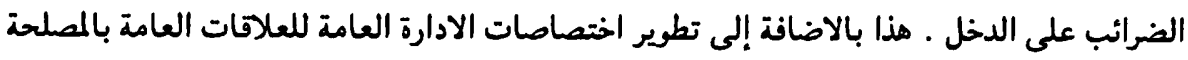
واستحداث شعب للعلاقات العامة بكل مأمورية .

أما الورقة الثالثة عشرة فقدمها دـ ـ اشرف حنا ميخائيل بعنوان تحديث مصر فى ظل المتغيرات

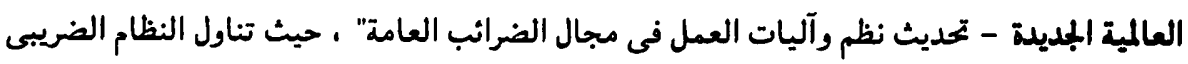

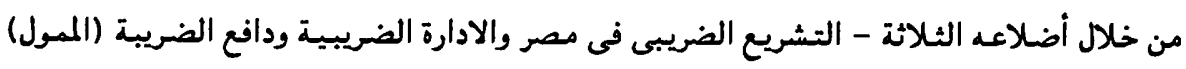


حيث تناول البحث الموضوع من خلال أربعة محاور أساسية : -

- المحور الأول استعرض تحديث التشريع الضريبى فى مصر وتطور أسعار الضريبة مقارنة

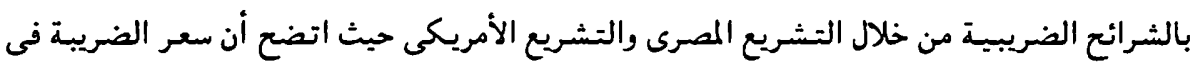

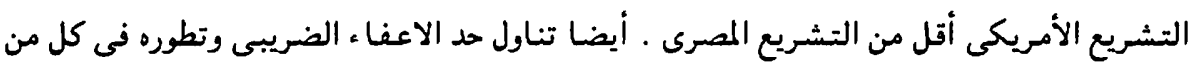

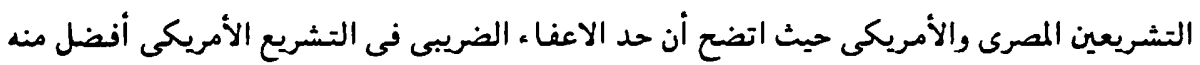



وشرح المحور الثانى من الدراسة تحديث الادارة الضريبية وحقوق وسلطات الادارة الضريبية

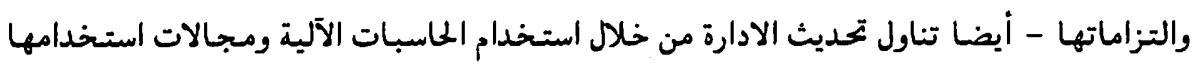

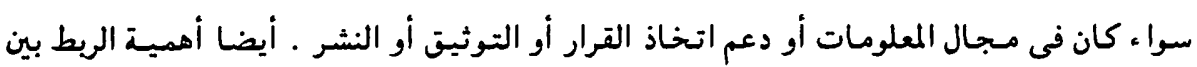

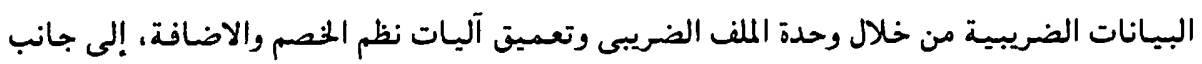
أهمية تحديث وتطوير الموارد البشرية للادارة الضريبية .

وكان المحور الثالث عن تحـديث الممول المصرى من خلال التوازن بين الممول والادارة الضريبية

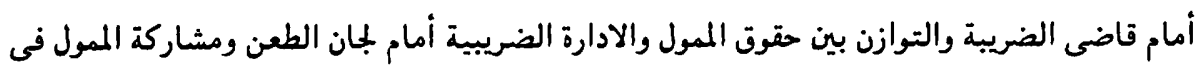
بعض مهام الادارة الضريبية . انتهت الدراسة إلى بعض التوصيات كان أهمها التالى : - العمل على تحـديث التشريع الضريبى من خلال توسيع الشرائح الضريبيـة وتخفيض سعر


كميا. - أهمية تحديث الادارة الضريبية من خلال استخدام الحاسبات الآلية ونظم المعلومات ووحدة الملف الضريبى والتوسع بنظام الخصم والاضافة . - أهميـة تحديث الممولين من خلال التوازن بين الممول والادارة الضريبية والعمل على استقرار العلاقة بين الطرفين من خـال الحقوق والوإجبات بالاضـافة إلى تعسيق اشتـراك الممولين في اتخاذ

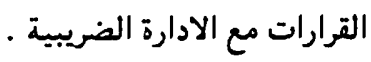

